\title{
Um olhar sistêmico
}

\section{sobre a crise norte-americana}

\author{
CHRISTIAN CARVALHO GANZERT I, \\ LEONARDO AUGUSTO AMARAL TERRA II \\ e DANTE PINHEIRo MARTINELLI III
}

\section{Introdução}

$\mathrm{O}$ TERMO CRISE é usado para uma vasta gama de situações, mas seus significados não variam muito, ocupando um campo semântico bem delimitado na literatura da área de administração de contingências. No contexto organizacional, Mitroff e Anagnos (2000, p.34) veem a crise como "um evento que afeta ou tem o potencial de afetar a organização como um todo". Segundo Ulmer, Sellnow e Seeger (2006, p.53), "uma crise pode criar uma oportunidade de mudança para as operações e atividades fundamentais". Além disso, sinaliza para uma mudança de premissas e de visão de mundo, representada pela palavra alemã Weltanschauung.

Frequentemente, a crise organizacional tem seu início fora da organização ou em uma divisão específica que está conectada ao resto da companhia. Se a turbulência ocorre em uma pequena e isolada parte da organização, não é vista como uma crise. O elemento mais característico de uma crise é a sua capacidade de romper as fronteiras entre as subdivisões organizacionais. Mas é difícil prever como um problema aparentemente inofensivo, em um setor pequeno de uma estrutura, irá impactar nas outras divisões da organização. Se o problema é transmitido através das relações do sistema (constituído pelas divisões organizacionais) e amplificado, tornando-se maior e mais complexo, tem-se um bom exemplo de crise. Há uma preocupação maior atrelada à constatação de uma crise pelo fato de que "nenhuma organização, pública ou privada, está imune das crises" (ibidem, p.3).

Essas características de uma crise remetem diretamente a uma propriedade típica dos sistemas complexos. Um sistema é, pela definição de Bailey (1994, p.44), "um conjunto restrito de componentes inter-relacionados que tem valor de entropia abaixo do máximo". Nesse tipo de entidade, as interações oriundas de uma rica rede de relações podem atuar amplificando qualquer mínima perturbação, por meio de laços de feedback, levando a organização do sistema a um novo patamar qualitativo (Ashby, 1964; Capra, 2006). Essa característica se configura em uma ameaça contra sua integridade e significa uma ameaça contra toda a estrutura. Nesse contexto, pode-se dizer que as crises são situações típicas 
da dinâmica sistêmica e podem ser vistas como o resultado de falhas ocorridas na dinâmica de interações, muitas vezes originadas de mal-entendidos contextuais ou mesmo de má interpretação dos objetivos propostos que são amplificadas e se propagam por todo o sistema.

Ao transpor a ideia de sistemas para o ambiente social Wiener (1954) também se ancora na percepção de que a dinâmica de tais sistemas está constantemente lutando contra a tendência natural do crescimento da entropia. $\mathrm{O}$ conceito de entropia foi importado da teoria termodinâmica, e acoplou-se à teoria matemática da informação pela obra de Shannon $(1948,1949)$. Na teoria de Wiener (1954), a entropia é uma medida de desorganização, assim como a informação, conduzida por um grupo de mensagens, é uma medida de organização. Essa visão é uma adaptação feita por Shannon (1948) do postulado da termodinâmica que reporta a tendência natural das partículas de um sistema de estabelecerem-se em níveis de mínimo consumo de energia, em que os componentes não se autoarticulam dinamicamente. Dessa forma, um sistema pode ser visto como um tipo de organização, ou uma tentativa de superar a entropia.

Os sistemas sociais são mais difíceis de definir e predizer, uma vez que, segundo Gharajedaghi (1999, p.12), podem ser classificados como sistemas de múltiplas mentes. O sistema social é um tipo de organização, com comportamento específico e dinâmica peculiar, considerado como "uma associação voluntária de membros que possuem propósitos e que manifestam uma escolha de fins e meios". Portanto, como sinaliza Gharajedaghi (1999), a variável crítica é o propósito, uma vez que os grupos e os indivíduos têm seus próprios propósitos e objetivos. Não obstante, algumas vezes este não se manifesta como uma escolha, mas como uma imposição do ambiente, construída por coerção cultural (Ogburn; Nimkoff, 1953).

Em um sistema, os propósitos e finalidades estão baseados em interesses individuais com assuntos constituintes convergentes. Os indivíduos de um arranjo sistêmico (um grupo, uma comunidade ou uma organização) estão conectados por regiões de interesse comuns, que corroboram o propósito coletivo. Quando um empregado da indústria vai para o trabalho a cada manhã, ele o faz motivado por uma necessidade individual, que pode ser o merecido salário ou a simples satisfação da prática de seu trabalho. Seus colegas certamente poderão ter diferentes motivações para trabalhar. Mas o trabalho coletivo desenvolvido tem um propósito maior: produzir algo que tenha algum tipo de valor para o mercado - ou outro grupo de pessoas. Esse propósito coletivo faz mais sentido para o empregador e para a sociedade como um todo do que para o empregado, o indivíduo que se juntou ao jogo para satisfazer suas próprias necessidades. Essa é uma parte do antagonismo envolvendo os conceitos de coletivo e individual, como descrito por Linton (1952), e é o argumento central dos maiores problemas em torno dos sistemas sociais.

De acordo com Degushi (2004, p.5), o sistema econômico é o coração 
do sistema social, descrito como "uma sociedade baseada em agentes, em que agentes autônomos se relacionam e aprendem mutuamente". Seu trabalho se relaciona com o estudo dos "sistemas socioeconômicos complexos com múltiplos agentes autônomos e tomadores de decisões" (ibidem, p.6). Uma vez que os múltiplos agentes são motivados por diferentes fatores e têm uma ampla variedade de possíveis ações para a interação social, acabam por expandir a complexidade das predições macroeconômicas por conta do imprevisível comportamento dos indivíduos e do resultado de suas interações. Como Tesfatsion (2003, p.263-4) descreve, "o resultado de uma dinâmica sistêmica complicada de cadeias causais recorrentes conectando comportamentos individuais, redes de interação e resultados da interação social".

Olhando do ponto de vista do indivíduo, a articulação dinâmica entre os demais indivíduos, grupos e elementos sistêmicos (como lugares e recursos) pode ser vista como uma entidade intitulada "ambiente". A todo instante, os indivíduos estão diante de um jogo de "entradas" e "saídas" (interação) com o ambiente, tentando adquirir resultados que satisfaçam suas necessidades individuais. O ambiente tem diferentes níveis, conforme a Figura 1, adaptada de Rothwell (2000, p.26). A interação entre o coletivo e o individual é recursiva, admitindo que os grupos ajam como indivíduos quando com um ator no nível ambiental imediatamente superior. Para o escopo individual, qualquer coisa situada um nível adiante de sua esfera é considerada parte do ambiente, iniciando-se pelo grupo de trabalho, ou o ambiente de interação com sua equipe. Quando assumido o grupo de trabalho como um agente, o departamento passa a ser o nível ambiental imediatamente superior a se relacionar. Essa descrição da interação sistêmica é um artifício pedagógico que possibilita a compreensão dos conceitos desenvolvidos por Ashby (1964).

A complexidade de um sistema é determinada pela interação de quatro elementos: o número de componentes do sistema, como eles interagem entre si, os atributos dos componentes e o nível de organização do sistema. O último elemento tem uma estreita relação com as regras que guiam as relações e interações no interior do sistema. A proliferação da complexidade é esperada quando se inicia a expansão das relações internas e externas (Jackson, 2000). Em um sistema complexo, as saídas não podem ser descritas com precisão. Quando a complexidade cresce, o conhecimento sobre todos os estágios do sistema e seus processos internos e a capacidade de predizer suas saídas são mais limitados. Um sistema com grande complexidade poderá ter um comportamento caótico de respostas para as entradas, pois os resultados de suas interações são mais difíceis de ser controlados e podem ser amplificados de tal forma que o torna extremamente sensível às condições iniciais. Essa sensibilidade faz que duas possíveis trajetórias, inicialmente próximas, se afastem de maneira dramática no decorrer do tempo, o que, em última instância, pode frustrar qualquer tentativa de previsão das saídas futuras do sistema (Gleick, 1988; Prigogine, 2002). 


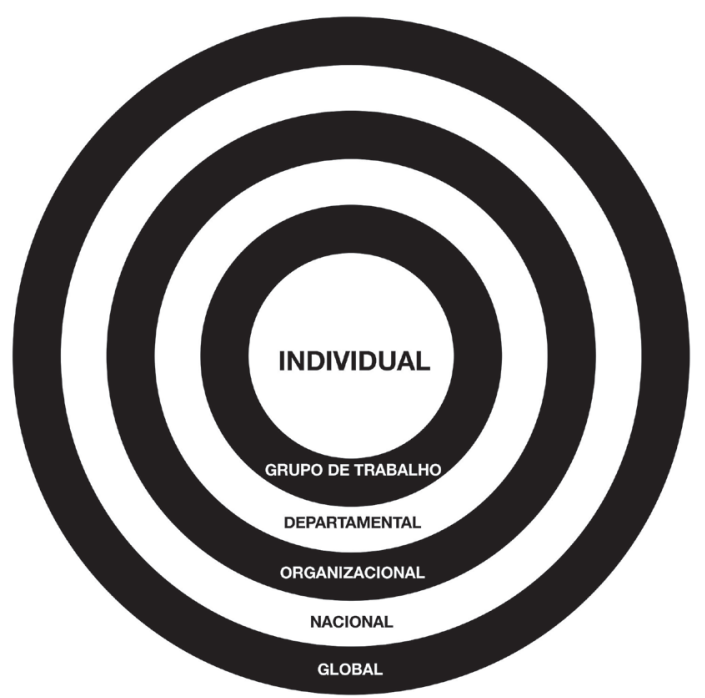

Figura 1 - Níveis de interação ambiental.

Fonte: Adaptação de Rothwell (2000, p.26).

No mercado financeiro, todos os tipos de investimentos possuem riscos, maiores ou menores, dependendo das particularidades inerentes à sua composição e finalidade. Alguns investimentos financeiros, como o subprime, encontram-se relacionados por meio de interações que criam profundos laços de realimentação, capazes de tornar as previsões pouco efetivas ou difíceis de serem exatas. Isso porque, nessa complexa rede de relações "uma causa inicial se propaga ao redor das articulações do laço, de modo que cada elemento tenha um efeito sobre o seguinte, até que o último realimenta (feedbacks) o efeito sobre o primeiro elemento do ciclo" (Capra, 2006, p.59). Em um cenário com múltiplas interações, essa dinâmica leva a uma condição em que causa e efeito podem não ser claramente isoláveis (Ashby, 1964; Morin, 2007).

Tomando por base esses princípios, é possível observar as características da política de controle do governo Bush para com os mercados financeiros. Nela percebe-se que se propiciou a emergência de fenômenos que foram amplificados por complexos laços de realimentação que tornaram virtualmente impossível o conhecimento preciso do futuro e culminaram com o agravamento da crise que foi realimentada pelo próprio sistema. Na prática, o mercado estava à deriva, sem um controle que admitisse a previsão dos desdobramentos das interações entre agentes do sistema. Conforme lembra Lethbridge (2008), muitos dos custos dessa crise decorreram exatamente da tentativa de prever, a partir do passado e do presente, fenômenos transformadores que são quase sempre imprevisíveis.

Uma vez que o nível de controle de um sistema pode ser medido pela intensidade de regras restritivas às ações dos agentes (Ashby, 1964), o mercado financeiro americano pode ser propriamente dito "descontrolado", sob as premissas do pensamento neoliberal. Quando os agentes não possuem a capacidade 
de antever as consequências dos seus atos, sob o ponto de vista sistêmico, deverá haver algum mecanismo de regulação de suas atividades, para manter a integridade do sistema e dos demais agentes envolvidos. Quando o governo abdica do papel de controlador, os laços de realimentação podem amplificar ou atenuar determinadas perturbações contrárias aos interesses de manutenção da identidade do sistema, levando-o a um patamar qualitativo indesejado (Espejo et al., 1996), onde o caos torna virtualmente impossível qualquer predição dos resultados.

\section{A bolha imobiliária e a quebra da economia: lições sobre interdependência sistêmica}

De acordo com Shiller (2008, p.1), "as forças libertas pela crise do subprime vão provavelmente ecoar durante anos, promovendo mais e mais danos colaterais". Essa afirmação não é novidade para os teóricos de sistemas, para quem as consequências de uma interação sistêmica geram implicações para uma série de elementos que coexistem no mesmo ambiente. Entretanto a observação simboliza a importância dos eventos desdobrados a partir da crise do subprime.

Assim como qualquer consequência sistêmica, haverá reverberação por muito tempo no sistema financeiro. A real diferença entre a maior parte das saídas de sistemas equilibrados e aquelas observadas durante a crise do subprime é a intensidade de seus resultados. Ao escopo da administração de sistemas, algumas saídas são bem-vindas porque melhoram a posição dos agentes que iniciaram uma ação de interação, seja em um tema específico, seja em outro. Outras saídas são indesejáveis, pois geram perdas aos agentes, obrigando-os a gastar recursos para recuperar o conforto de sua posição anterior. A crise do subprime foi, para analistas como Shiller (2008), muito pior do que o conjunto das mais indesejáveis saídas possíveis. Significou, na verdade, o acúmulo de diversas saídas indesejáveis do sistema, gerando uma enorme perda que não poderia ser absorvida de uma vez só pelos agentes sistêmicos.

Para entender completamente as razões que levaram o sistema financeiro americano a encontrar a crise é necessário observar o processo histórico do método de acumulação que contaminou o mercado imobiliário dos Estados Unidos. Para Dell'Ariccia, Igan e Laeven (2008) a crise dos subprime - como ficou conhecida - teve suas origens a partir de um imperceptível e intrincado relacionamento sistêmico entre as ações de concessão de crédito do sistema financeiro e as reações do ambiente a tais ações. Muitas dessas relações se iniciaram anos antes de seus desdobramentos e foram seguidas por uma série de outras interações que amplificaram suas consequências até levarem ao colapso da própria dinâmica do sistema financeiro norte-americano com consequências devastadoras para toda a economia global. Em síntese, pode-se dizer que se tratou de uma bolha especulativa com peculiaridades singulares a serem mantidas em mente.

A primeira das peculiaridades pode ser condensada em uma questão: quanto vale uma casa? Como transformar o valor da moradia em um preço justo? Obviamente, a resposta a essa questão depende de diversas variáveis, algumas 
não passíveis de mensuração linear, tais como preferências individuais e aspectos culturais atrelados à escolha, conforme previram os economistas clássicos. Essas variáveis constituem um valor imaginário inicial que se transformará em preço pelo equilíbrio entre oferta e demanda. Os preços das residências nos Estados Unidos quase triplicaram na maior parte do país entre 1997 e 2006 (Schechter, 2008, p.5), o que pode ser detectado pela Figura 2. Mas a população, os custos de construção e as taxas de longo prazo não atingiram a metade desse crescimento (Shiller, 2008). Geralmente, as abordagens clássicas explicam o aumento dos preços por um aumento de demanda justificado pelo aumento populacional, e até mesmo pelo aumento da renda, que impactaria no aumento de outras variáveis macroeconômicas. Aparentemente, nada disso ocorreu. Então, como explicar o aumento do preço das casas?

A explicação mais lógica poderia ser a hipótese de crescimento do rendimento das famílias aliado ao crescimento de vagas de emprego. Mas de 1995 a 2004, apenas no estado da Califórnia, a média dos preços de casa subiu cerca de $284 \%$, enquanto o crescimento de postos de trabalho cresceu apenas 25\% (Wolk, 2005). Em Nova Jersey, por exemplo, a média de crescimento dos preços de residências foi de cerca de $220 \%$ no mesmo período, enquanto o crescimento de postos de trabalho não atingiu os $15 \%$. San Diego teve um crescimento da renda nominal média de 94,6\% entre 1990 e 2005 (inflação incluída), o maior da Califórnia (Thomas, 2007). Enquanto isso, as residências em San Diego acumularam um crescimento de preço de mais de $150 \%$ no curto período de 2000 a 2005 (Data360, 2008). Até mesmo nas cidades em que houve os maiores aumentos de rendimentos, os preços das residências cresceram muito mais do que a expectativa.

A explicação oficial para o fenômeno veio apenas depois do início da crise, quando muitos analistas culparam a abundância de crédito imobiliário para o crescimento da demanda por casas. Segundo os principais analistas, a forma "fraudulenta" com que os créditos eram aprovados gerava uma instabilidade no sistema que poderia deflagrar, em médio prazo, o aumento vertiginoso da inadimplência (Shiller, 2008). Havia então uma estreita relação com o sistema financeiro. Essa é uma característica típica de sistemas sociais abertos, que podem ser estimulados por outros sistemas interconectados, ainda que esses possuam finalidades diferentes (Ashby, 1964; Terra; Passador, 2016). No caso em questão, o próprio sistema financeiro que alimentava o processo visando obtenção de lucros cada vez maiores através de seus processos especulativos.

Pelos princípios da economia clássica, quando a demanda é maior do que a oferta, há a iminência de uma tendência de aumento de preços. Mas essa afirmativa apenas se justificaria se, e apenas se, a oferta de casas não acompanhasse a demanda. A interdependência entre oferta, demanda e preços permite a observação do problema pelas perspectivas desses três elementos, e em todas elas seu ajuste é temporário, até a obtenção de um novo ponto de equilíbrio. Conforme Takayama (1985, p.300): 
Se quisermos resumir tanto os processos temporários e os processos de curto-prazo, podemos simplesmente assumir que tanto demanda quanto produção se ajustam automaticamente ao preço [...] e podemos que o ajuste do preço é aquele que descreve o mecanismo do equilíbrio final.

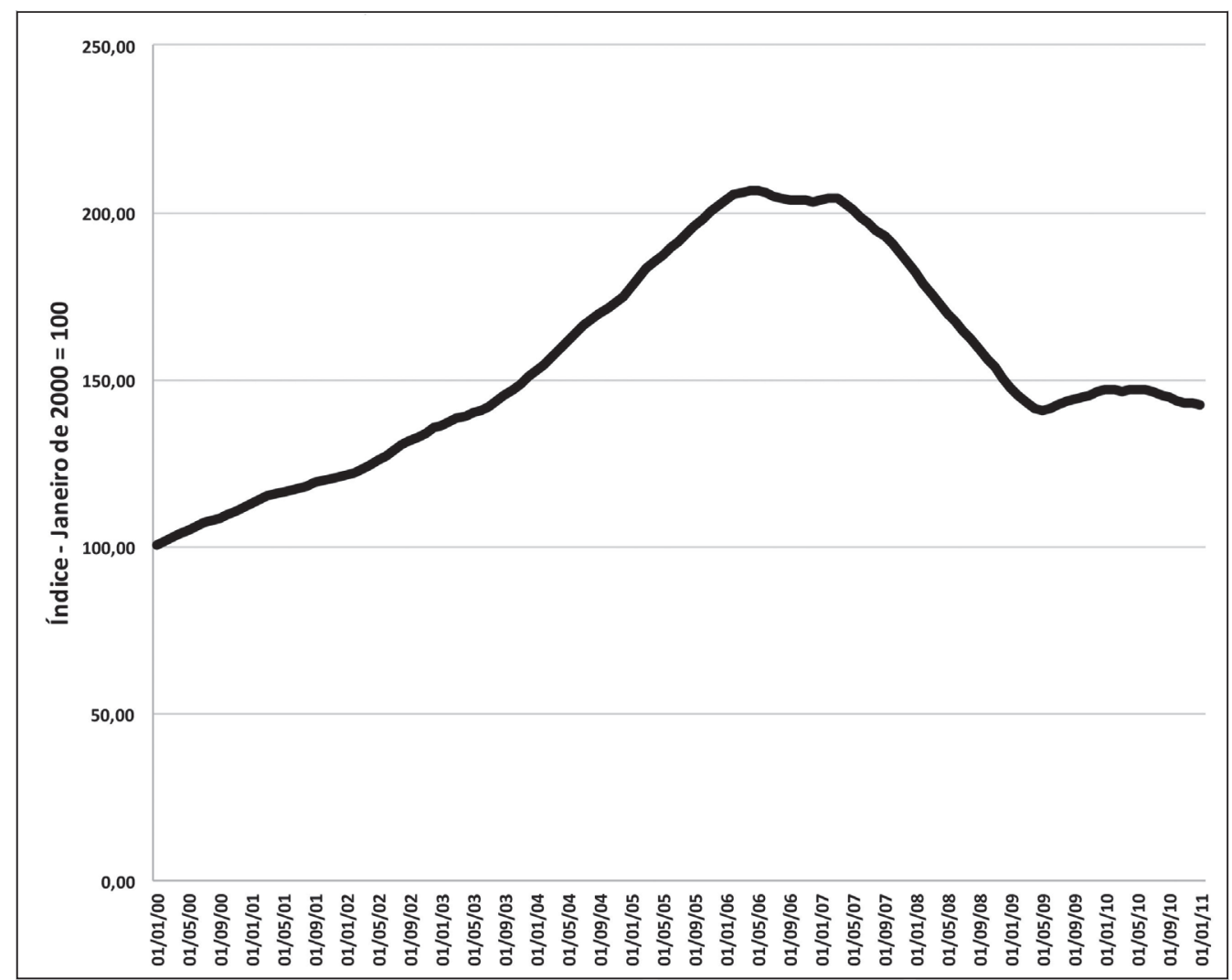

Figura 2 - Índice composto dos preços de imóveis nos Estados Unidos.

Fonte: Data360 (2008).

Logo, existem duas possibilidades a serem observadas para que seja considerado um aumento contínuo dos preços das casas. Primeiramente, o aumento da demanda. Teoricamente, existiria um momento em que os preços se estabilizariam em um nível que desencorajaria os compradores. Isso não aconteceu por cerca de dez anos no modelo observado nos Estados Unidos, um período muito maior do que o esperado para os ajustes entre oferta e demanda. Como essa possibilidade não se consolidou, passa-se à segunda possibilidade, em que a oferta poderia estar conectada à dinâmica de outros sistemas paralelos. O setor de construção está limitado pelo setor industrial - um dos mais evidentes subsistemas conectados ao subsistema delimitado pelo mercado imobiliário. No caso dos preços crescentes no mercado americano de residências, se a demanda impulsionasse o crescimento das taxas de oferta, os preços do setor de construções cresceriam intensamente, o que de fato não aconteceu (Shiller, 2008). 
A questão que representaria o centro do problema seria a abundância de dinheiro em posse das famílias, permitindo a explosão da demanda, e não a necessidade empírica de um maior número de casas. Se a população não cresceu - quase estabilizada em média em 1\% ao ano em todo o país (Day, 2008) - na mesma medida que os preços, não havia necessidade real para um maior número de residências. E se os salários não acompanharam sequer a metade do crescimento dos preços das residências na maior parte do país (Thomas, 2007), a abundância monetária que propeliu o crescimento da demanda somente poderia encontrar respaldo no mercado financeiro, um sistema diretamente relacionado ao mercado de imóveis. Para finalmente se obter uma visão geral e mais contundente da crise deflagrada no mercado de imóveis, é necessário ter em mente que os mercados se relacionam como subsistemas de um sistema maior, a macroeconomia. Essa associação cognitiva não é simples, e demanda o conhecimento da estrutura macroeconômica internacional permeada pelos conceitos da Teoria dos Sistemas.

Assim como sinalizado por Reinhart e $\operatorname{Rogoff}(2008$, p.339):

como muitos analistas argumentaram, o imenso aumento dos preços do mercado americano de casas não era inteiramente uma bolha, mas justificada pela inovação financeira (incluindo as hipotecas subprime), assim como pelo fluxo estável de capital vindo da Ásia e exportadores de petróleo.

Esse argumento seria validado se as inovações financeiras se sustentassem pelo aumento contínuo da produção interna americana. Infelizmente, essa não era a mais evidente situação futura para a economia americana. E mesmo na melhor projeção possível, é impossível prever todas as ocorrências e o comportamento geral da dinâmica sistêmica de produção social. De acordo com Kregel (2008, p.8), "mesmo aqueles banqueiros que possuem melhor conhecimento geral acerca das condições competitivas locais e dos planos futuros dos concorrentes, não possuem um conhecimento melhor do futuro do que qualquer outra pessoa".

Como todo empréstimo está fundamentado na expectativa de pagamento que remunerará a decisão de não gastar do capitalista financeiro, essa apenas se sustentará sob a expectativa da consolidação dos resultados. O pagamento de parcelas de dívida financeira somente poderá se realizar ante a percepção de geração de riqueza - ou remuneração pelo trabalho - das famílias associadas ao processo produtivo. A riqueza, por sua vez, somente será gerada pela produção de bens e serviços. Qualquer tipo de riqueza gerada sem a produção de serviços ou produtos finais ou intermediários, em senso estrito, é um tipo de adiantamento de produção. Todo adiantamento se baseia na suposição de um nível futuro de riqueza. Mas há sempre um risco associado ao fato de, por alguma razão, a percepção futura de riqueza não atingir o que era esperado, ou mesmo não ocorrer. Essa é a premissa básica da análise de risco, e a questão mais importante associada à quebra do mercado de hipotecas americano (Shiller, 2008). 


\section{Nesse caso, para onde foi o dinheiro?}

Os Estados Unidos tiveram em 2008 um crescimento de Produto Interno Bruto (PIB) de cerca de 457 bilhões de dólares (BEA, 2009), o que representou um crescimento de $3,3 \%$. Significa que o PIB americano atingiu os 14,3 trilhões de dólares, o maior do mundo. Contudo, a dívida com hipotecas das famílias americanas era, em 2008, de cerca de 11 trilhões de dólares, quase 77\% do PIB (Folha Online, 2009). Todo esse débito era baseado na crença de que a economia americana possuía potencial para geração de riqueza e capacidade de distribuição para remuneração das famílias, que poderiam saldar suas dívidas. Entretanto, o crescimento do produto interno não se mostrou suficiente para sustentar os débitos das famílias americanas. Foram arrolados muito mais adiantamentos de produção do que poderiam efetivamente se materializar em riqueza, que significa que nem todos conseguiriam saldar suas dívidas. É um fenômeno natural quando há mais obrigações do que recursos aferidos. Processo esse que foi amplificado por uma complexa dinâmica de relações especulativas.

Se as famílias pudessem saldar as dívidas contraídas, parcela a parcela, através do recebimento regular de salários compatíveis com seu orçamento financeiro, até mesmo o desumano ritmo dos juros do crédito subprime (tido como responsável pelo crescimento vultoso dos preços do mercado de imóveis, pela verificação de risco de crédito fraudulenta em sua concessão a juros exorbitantes) não causaria tantos problemas. Ainda haveria o risco inerente à opção das famílias pelo não pagamento das dívidas em um caso de desvalorização dos imóveis. Contudo, no limite, ainda que os preços das casas caíssem vertiginosamente, se a renda das famílias se mantivesse pela produção real de riqueza, pode-se dizer que haveria como saldar as dívidas contraídas. Entretanto, esse não foi o contexto real.

Nesse contexto, a primeira tentação para os analistas econômicos é basear a explicação no fato de que a bolha especulativa imobiliária teria que estourar algum dia. Mas ainda que as famílias tivessem que arcar com o prejuízo da desvalorização de seus imóveis, mantendo as obrigações adquiridas pelo refinanciamento de suas hipotecas, os débitos seriam orçados pela renda de geração de riqueza. $\mathrm{O}$ aumento dos débitos poderia ser mantido pelo aumento da riqueza e dos salários. O problema está no fato de que os salários não cresceram à mesma taxa dos débitos. Entretanto, a produção americana de riqueza real perdeu muitas posições para os competidores externos - mesmo que esses estivessem financiados pelo capital americano.

O contexto macroeconômico internacional não é mais o mesmo do percebido na década de 1980. O pensamento neoliberal, presente nas decisões políticas da Era Bush, se baseava no contexto econômico existente entre 1971 e 1994. Os tempos mudaram desde então, mas houve a manutenção do modus operandi. Desde 1994, muitos desdobramentos ocorreram para agregação de um mercado internacional mais competitivo e integrado, o que reduziu a hegemonia dos 
produtos americanos em muitos aspectos. Não significa dizer que houve uma retração das vendas americanas, mas uma maior divisão da riqueza gerada pelo comércio internacional com as outras nações do mundo, especialmente com as antes consideradas nações em desenvolvimento terceiro-mundistas.

A Índia, por exemplo, teve um crescimento do PIB de cerca de 9,6\% no ano fiscal de 2006-2007 (Igovernment Bureau, 2008). A projeção do governo indiano para 2007-2008 foi de um crescimento de PIB de cerca de 1,6 trilhão de dólares. O valor absoluto do PIB indiano é pelo menos doze vezes menor do que o PIB americano, mas seu crescimento é mais de duas vezes maior - e crescendo. As condições que propiciaram o estabelecimento de um desenvolvimento contínuo e intensivo das qualidades competitivas da indústria indiana são as mesmas encontradas em países como China, Rússia e Brasil. Salários relativamente baixos, aliados a uma boa estrutura para suportar as necessidades do processo de crescimento, assim como boas universidades e centros de pesquisa, força de trabalho especializada disponível e investimentos pesados, tornando possível a melhoria da competitividade desses países no mercado internacional (Wilson; Purushothaman, 2003). O resultado foi o abocanhamento de uma parte maior da riqueza mundial gerada, o que significa dizer uma redução da parcela relativa cabida aos Estados Unidos e, dessa forma, à divisão relativa da geração de riqueza para as famílias americanas.

Em 2002, por ocasião de um colóquio no Rio de Janeiro, a economista Maria da Conceição Tavares predisse que a transnacionalização dos fatores de produção americanos para a China poderia criar um processo de deflação que poderia ser enxergado como um claro sinal de quebra da hegemonia americana frente ao comércio internacional. ${ }^{1}$ Primeiramente, as companhias americanas transferiram para a Ásia muitas de suas plantas produtivas, para reduzir os custos operacionais (muito altos nos Estados Unidos). Seus pagamentos, antes feitos em território doméstico, começaram a ser repassados para outros países. Ainda que os lucros se intensificassem, fato ocasionado pela redução dos custos, esses custos não eram mais devidos à remuneração de fatores de produção em território americano para agentes econômicos dos Estados Unidos. Para ganhar mais, a indústria americana iniciou um processo de sinergia produtiva com produtores estrangeiros, o que intensificou a maior divisão da parcela de riqueza dedicada às famílias americanas. Em outras palavras, significa a transferência de riqueza baseada na maior competitividade dos fatores de produção dos países outrora periféricos do sistema capitalista. A corrida por maiores lucros baseada na transferência de processos onerosos para polos industriais mais competitivos é uma das principais razões - ainda que indireta e de difícil associação - da estagnação da remuneração das famílias americanas e, consequentemente, da inadimplência nos diversos mercados de acesso às classes trabalhadoras, inclusive o de hipotecas.

Nesse contexto, seria esperado que o aumento contínuo dos débitos das famílias americanas derivaria em inadimplência generalizada. Não se trata apenas 
de uma crise do subprime, sendo previsível a ocorrência do mesmo processo em outros segmentos em curto, médio e longo prazos. Outros adiantamentos de riqueza deixaram de ser pagos, sinalizando que o subprime não foi exatamente o grande vilão que iniciou a crise, mas o apontamento de que algo estava imensamente errado no modelo americano de capitalismo financeiro. Portanto essa crise é apenas uma parcela de um todo maior cuja origem remete ao adiantamento de riquezas não realizadas, mas é fruto de todo um conjunto de amplificações provocadas pela complexa dinâmica especulativa dos mercados financeiros.

\section{O papel da inteligência na percepção da crise}

Como observa Shiller (2008, p.23-4) sobre a implantação da modalidade subprime, "eles [governo e administradoras de bancos de hipotecas] perderam a conta do tipo de administração de risco necessário para dar suporte à crescente e complexa maquinaria necessária para lançá-la". Uma das ferramentas mais importantes seria, obviamente, a análise de contexto. Toda a situação estaria resolvida se, no ato de lançamento da modalidade subprime, o contexto fosse avaliado e simulado em condições futuras, sob auspício das agências reguladoras. Mas o governo não deveria ser o único responsável pelo entendimento do contexto geral associado ao mercado imobiliário. Os demais agentes econômicos deveriam possuir a habilidade de fazer suas próprias projeções baseadas em seu ponto de vista sobre o contexto geral.

Comprar apenas porque os demais estão comprando é uma atitude coletiva que supõe a necessidade de uma liderança entre os agentes. Se há líderes iniciando as tendências, o governo deveria identificá-los e trabalhar próximo a eles, intervindo direta ou indiretamente no mercado, para que não haja consequências não desejadas para a economia como um todo. A única forma de se exercer esse papel é manter a consciência governamental sobre os desdobramentos das atividades desempenhadas no interior do mercado pelos seus agentes. O governo deveria, enquanto regulador, rastrear ativamente tudo o que ocorre no mercado e intervir quando necessário. Em síntese, sob a lógica proposta pelo modelo de sistemas viáveis de Beer (1995) significaria que o governo deveria atuar como um controlador atenuando possíveis comportamentos desviantes que pudessem alimentar perturbações indesejadas em vez de combatê-las.

Portanto, os agentes de mercado deveriam encontrar respaldo nas leis e ferramentas de regulação amparadas pelo governo. Mas sua interação deve passar pela análise majorada e consciente, baseada em todo tipo de informação disponível e amplamente acessível sobre o ambiente de negócios. A inteligência tem que ser uma prática constante dos agentes econômicos, seja qual for a relação estabelecida com o ambiente externo. Há diversos sentidos atribuídos ao termo inteligência, relacionados a uma vasta gama de relações estabelecida entre agentes econômicos e ambiente, na busca por informações relevantes que possam auxiliar na manutenção da existência dos agentes sistêmicos (March, 1999). 
$\mathrm{O}$ agente em ação direta para com o ambiente não consegue escapar à percepção das informações oriundas deste, uma vez que todo tipo de estímulo recebido pelo indivíduo tem a possibilidade de ter um sentido associado, e consequentemente ser considerado informação (Dantas, 2003). Significa dizer que em interação com o ambiente, não há como escapar às informações. Entretanto, as informações de maior relevância são mais difíceis de ser acessadas que as de menor importância.

O custo associado à obtenção da informação de maior importância é sempre mais expressivo, sendo essas aquelas relacionadas à economia de recursos ou à obtenção de maiores lucros. Nos dias de hoje, sob a lógica do capitalismo informacional iniciado ao molde americano, a informação é um bem, muitas vezes o mais caro deles (Wiener, 1954). E se as decisões mais importantes são aquelas que envolvem maiores custos (Verplanken; Svenson, 1997), a informação associada a esse tipo de decisão tem um valor intrínseco maior que as demais. $\mathrm{O}$ papel da inteligência está diretamente relacionado com o manejo de informações relevantes para uma organização ou sistema, ou seja, aquelas que possam significar reduções de custo, aumento dos lucros ou manutenção da existência do sistema.

Conforme propõem Espejo et al. (1996), a função inteligência tem que prover subsídio para os processos decisórios. A consciência sobre o ambiente apenas poderá ser obtida através do bom desempenho da função de inteligência, baseada na coleta e no fluxo de informações relevantes, extraídas dos ambientes interno e externo.

Nos últimos anos, principalmente no mercado financeiro americano, o papel da inteligência tem sido (ou ao menos aparenta ter sido) negligenciado em diversos aspectos. Em primeiro lugar, houve falhas na percepção de sinais de incompatibilidade entre os débitos adquiridos pelas famílias americanas e a capacidade de produção de riqueza atual da economia do país. Em um segundo nível, houve falhas em prover informações que possibilitassem uma análise correta sobre os investimentos direcionados pelos agentes do mercado financeiro. Por último, a função de inteligência não deveria ter permitido que o modelo de hipotecas subprime fosse subvertido pelas necessidades dos "comerciantes de empréstimos", permitindo que esses amplificassem uma perturbação ao ignorar os riscos associados à expansão desmedida desse tipo de crédito, visando a simples obtenção de vantagens pessoais.

\section{Falha sistêmica ou remodelagem sistêmica: observações da Teoria dos Sistemas}

O reparo de sistemas comprometidos não é trivial - especialmente os econômicos. Em primeiro lugar, porque a teoria dos sistemas dissipativos afirma serem irreversíveis os saltos qualitativos de sistemas que passem por mudanças de identidade que se configurem como pontos de bifurcação (Prigogine, 2002). Em segundo lugar, porque há diversos elementos conectados à crise que estão 
baseados à impressão individual dos agentes econômicos, sustentados pela cultura de cada um dos mercados envolvidos. Essa percepção remonta ao alinhamento entre cultura e a situação de crise.

A cultura condiciona a ação dos agentes, agregando às suas percepções individuais de mundo os sentidos necessários para que realizem suas decisões (Culler, 1982). E o informacionalismo, termo utilizado por diversos autores de diversas vertentes, como Castells (2000) e Lojkine (1992), para descrever o estágio atual do capitalismo, está diretamente relacionado com um tipo asséptico de cultura, que não possui raízes que a conectem ao contexto regional, mas serve ao contexto internacional, um tipo de cultura da globalização permeada pelos dispositivos tecnológicos de informação (Santaella, 2003).

A cultura influencia, dessa forma, a ação dos agentes sistêmicos, uma vez que eles sofrem uma mudança de sua compreensão original de mundo com a adição de novos elementos culturais relacionados ao processo de globalização e disseminação das novas tecnologias. Essa compreensão de mundo é conhecida por Weltanschauung, uma expressão alemã que significa a visão única e individua- lizada de mundo, uma estrutura de ideias de percepções (Hiebert, 2008). Todo ser humano tem a sua própria impressão do mundo, baseada em suas experiências pessoais únicas na interação com o meio e outros seres humanos. A cultura estabelece um padrão comum de comunicação e interação, no qual os sentidos não são exatamente os mesmos para todos os agentes existentes, mas tem um núcleo de compatibilidade com os sentidos atribuídos aos signos por cada um dos agentes sociais que compartilhe a mesma cultura. Significa dizer que a cultura é essencial para a troca de informações, que proporcionará o desenvolvimento de ações no âmbito produtivo.

Se há a necessidade de mudanças no sistema produtivo, para consertar o mau funcionamento no ambiente econômico, ou levá-lo a um novo patamar qualitativo, o primeiro tema a ser analisado deverá ser o contexto cultural que serviu como propelente para gerar a crise estrutural observada. Um sistema econômico baseado em um padrão cultural inteiramente permeado por elementos que exacerbam o individualismo (coração do modelo de produção capitalista), o crescimento dos lucros (sejam quais forem os custos), a acumulação de riqueza (aquela do tipo individualizado), o adiantamento de riqueza para compensação futura (empréstimos, mesmo quando o futuro se mostra imprevisível diante de uma dinâmica caótica, e os recursos para saldá-los são cada vez mais raros) e a transferência de obrigações mais onerosas para agentes no exterior (até mesmo quando isso significa transferência da remuneração das bases domésticas para outros países, sob a ideia de aquisição de maior competitividade pela redução dos custos operacionais), é evidentemente insustentável em longo prazo.

Ironicamente, as ideias de liberalização dos mercados e globalização da produção (transferindo a indústria pesada e mais poluidora para os países em desenvolvimento) que era defendida pelos governos tipicamente neoliberais, como 
o de George Bush, contribuíram para o agravamento das dívidas das famílias americanas e o descrédito do mercado financeiro dos Estados Unidos. Mais uma vez, é possível traçar um panorama cultural associado a esses preceitos, típicos da ideologia americana ancorada em antigos princípios saxões que remontam à ascese protestante e à obtenção da salvação pelos méritos individuais conforme propusera Weber (1996).

Teoricamente, as premissas do livre comércio e a busca por maiores lucros pela redução dos custos de produção deveriam oferecer o aumento da riqueza, vendendo mais por preços mais baixos, estimulando a economia. Entretanto, esse aumento da riqueza somente foi percebido pela parte dos agentes econômicos que não está diretamente envolvida com o processo produtivo, mas estabelecida nos altos escalões das corporações. Com o deslocamento da produção para a periferia do sistema (países em desenvolvimento), os trabalhadores ficaram excluídos do processo de remuneração. Significa a demissão de uma grande parte da força de trabalho, com consequente ajuste dos níveis salariais mais básicos e aumento da inadimplência e falências. Todo o processo está associado a elementos da cultura americana que exacerbam a riqueza individual e tem a propriedade particular como um direito divino, perdendo o senso de interdependência sistêmica entre os elementos de um sistema socioeconômico.

É esperado que várias regiões do mundo continuem sofrendo de um período de certa instabilidade econômica por conta das perdas do sistema financeiro americano, uma vez que os Estados Unidos são um dos mais importantes investidores em países externos. Assim mesmo, países como Índia e China passaram quase intactos pela crise, com reduções de seu crescimento que não podem ser vistas como tão dramáticas quanto a americana. O PIB americano teve crescimento negativo de 1,03\% no primeiro semestre de 2009 (Financial Forecast Center, 2009), enquanto a China teve uma projeção de crescimento positivo do PIB de cerca de 7,2\% para 2009, e 7,6\% para 2010 (Economist.com, 2009). De acordo com Wilson e Purushothaman (2003, p.4-5), "a Índia possui potencial de mostrar maior crescimento nos próximos trinta e cinquenta anos. O crescimento deverá ser maior que $5 \%$ anualmente nos próximos trinta anos, e de mais $5 \%$ até 2050 se o desenvolvimento proceder com sucesso". Brasil e Rússia voltaram ao crescimento positivo em menos de seis meses depois do ápice da crise, apesar de ainda encontrarem-se em um ritmo de aceleração econômica menor do que aquele anterior à crise dos subprime.

As similaridades econômicas desses quatro países culturalmente tão distintos são baseadas em um ponto singular: controle da entropia. Os governos dos Brics, sigla que representa os quatro países (Brasil, Rússia, Índia e China e África do Sul), ainda estão mergulhados na ideia do maior controle dos mercados, para se prevenir de eventuais riscos de ruptura sistêmica o que novamente remete à ideia do modelo de sistema viável de Beer (1995). Essa característica foi providencial ante a crise, apesar dos diversos problemas que os países ainda possuem, 
tais como corrupção e inequidade social (menor vista no caso da China, por conta do regime político, mas ainda assim existente).

Além dos Brics, aqueles outros países que antes tinham sua produção baseada no know-how com envio de royalties aos países mais desenvolvidos estão agora inseridos em um processo contínuo de inovação tecnológica, derivado das conexões estabelecidas com centros de excelência em desenvolvimento e produção de tecnologia de ponta, fomentando um Sistema Nacional de Inovação (universidades, empresas e institutos de pesquisa) conectado à rede global de recursos humanos e financeiros, suportada pelo fenômeno de "Brain Circulation” (Saxenian, 2006).

Em uma das mãos, todo o sistema econômico americano está comprometido pelo aumento das dívidas das famílias americanas, enquanto na outra mão, os países de industrialização tardia vinham conquistando cada vez melhores posições na estrutura econômica internacional - não exatamente pela melhoria de suas condições de vida para a população, mas pela sustentação de um bom (mas nem sempre excepcional) aumento do PIB, pautado por um modelo de desenvolvimento nem sempre sustentável, como ficou evidente na situação das economias Russa e Brasileira em meados da década de 2010.

Se a economia global pode ser interpretada como um metassistema (Plotnitsky, 1994), constituído por sistemas econômicos nacionais independentes, mas articulados entre si, é possível dizer que há cerca de dez anos observa-se um rearranjo sistêmico com consideráveis mudanças para a hegemonia econômica em escala geopolítica. O rearranjo é um artifício típico da manutenção sistêmica, no intuito de tornar mais longeva a existência do sistema social, pelo qual novos agentes tomam o lugar dos agentes antigos sem mudar a finalidade geral do sistema - e normalmente manter suas premissas mais significativas (Buckley, 1967).

No caso do capitalismo, a premissa mais relevante a ser mantida com o rearranjo sistêmico é o individualismo - o elemento que melhor embasa o contexto cultural capitalista. A busca por maiores lucros, se finalmente quiser alcançar a sustentabilidade sistêmica, deverá estar alinhada à equidade entre os sistemas internos e externos, o que sob a influência do individualismo enquanto elemento cultural determinante do sistema se torna uma possibilidade distante de se concretizar, mas ainda possível. A solução repousa em mudanças substanciais na cultura que embasa o sistema e no reconhecimento da necessidade de um agente regulador que aja como amplificador ou atenuador de perturbações oriundas de inciativas individuais que possam afetar toda a dinâmica do sistema.

\section{Considerações finais}

A crise americana não se baseia somente nos problemas originados pelo sistema financeiro, por ocasião do colapso das hipotecas subprime. É, na verdade, um processo derivado de uma contínua externalização da produção que não encontrou substitutos para a remuneração das famílias americanas, transferindo 
parte do crescimento de sua renda para outros países. O capitalista americano ganhou mais, mas deixou de dividir seus ganhos com seus compatriotas da classe trabalhadora. Esse processo foi amplificado por uma complexa rede de especulação que permitiu que as famílias mantivessem seu endividamento enquanto sua remuneração parou de crescer a passos largos. Isso não significa que houve queda da renda das famílias, mas que essa não acompanhou os débitos, tendo seu ritmo reduzido pela externalização da produção. Ainda assim, as famílias americanas deram continuidade ao processo, articulado pelo sistema financeiro, de adiantamento de riqueza - ou a simples tomada de financiamentos.

Ainda que tenha havido intensos efeitos colaterais para a economia americana, apesar do enriquecimento da classe detentora das companhias e meios de produção (agora localizados na periferia do sistema), para os países de desenvolvimento tardio e maior regulação do mercado financeiro a transferência de renda pela internacionalização da produção e o estouro da crise significaram uma sensível melhora de sua participação na economia global.

A globalização, apesar de fortalecer a inequidade e transformar os problemas locais em globais, ofereceu uma condição de destaque para aqueles países com custos mais competitivos - um benefício originado pelos anos como fornecedores de matéria-prima e produtos de baixo custo na periferia do sistema, diminuindo a valorização do fator humano na produção. Agora, com a melhoria de sua competência tecnológica, estão competindo em um novo nível, na posição de países como os Estados Unidos e as outras nações capitalistas tipicamente hegemônicas.

Assim como a Teoria dos Sistemas aplicada à sociedade sinaliza, essa é uma evidência de um salto qualitativo dos padrões sistêmicos macroeconômicos, ocorrido pela valorização da riqueza individual - a qual permite o descolamento dos investidores para as questões de ordem nacional, voltando seus investimentos para o exterior em detrimento do contexto nacional. Como salienta Bauman $(1999$, p.15):

as pessoas que investem - os acionistas - não estão de forma alguma presas no espaço; elas podem comprar qualquer participação em qualquer bolsa de valores e através de qualquer correlator, e a proximidade ou distância geográfica da companhia será com toda a probabilidade a consideração menos importante na sua tomada de decisão de comprar ou vender.

Uma vez que os elementos da ideologia neoliberal lideraram as ações dos agentes econômicos por muitos anos, abrindo as portas para um modelo de mercado global integrado, os valores suportados pelo individualismo propeliram a mudança estrutural dos níveis mais básicos (indivíduo) aos mais gerais (nações) do sistema socioeconômico. Ainda que não se estabeleça um peso de valor moral sobre isso, a reformulação da estrutura interna do capitalismo rearranja as relações sociais e macroeconômicas, além de fortalecer um comportamento sistêmico básico: ainda quando alguns ganham e muitos perdem, o sistema sobrevive, 
amparado pelas mudanças sistêmicas encadeadas por sua mínima parcela, o indivíduo. Nesse contexto, este artigo não considera abranger a infinidade de variáveis que contribuiu para a amplificação que proporcionou o salto qualitativo que culminou com a crise financeira de 2008, mas propõe que a cultura deve ser o principal foco dos intentos de análise do atual contexto socioeconômico global.

\section{Nota}

I Informação verbal coletada da professora Maria da Conceição Tavares no seminário "Reformando as Reformas: finanças e ambiente", realizado em novembro de 2002, no Rio de Janeiro, Brasil.

\section{Referências}

ASHBY, W R. An introduction to cybernetics. Michigan: University of Michigan, 1964. BAILEY, K. D. Sociology and the New Systems Theory: toward a theoretical synthesis. New York: State University of New York Press, 1994.

BAUMAN, Z. Globalização: as consequências humanas. Rio de Janeiro: Jorge Zahar, 1999.

BEA - BUREAU OF ECONOMIC ANALYSIS. News Release: Gross Domestic Product (GDP). Washington, 27 feb. 2009. Disponível em: <http://www.bea.gov/newsreleases /national/gdp/gdpnewsrelease.htm>. Acesso em: $1^{\circ}$ mar. 2009.

BEER, S. Brain of the firm. Wiley, 1995. (Classic Beer Series).

BUCKLEY, W. Sociology and modern systems theory. New Jersey: Prentice Hall, 1967.

CAPRA, F. A teia da vida: Uma nova compreensão científica dos sistemas vivos. São Paulo: Cultrix, 2006.

CASTELLS, M. The rise of the network society, the Information Age: Economy, society and culture. Cambridge, MA; Oxford, UK: Blackwell, 2000. v.1.

CULLER, J. On deconstruction: Theory and criticism after structuralism. Ithaca: Cornell University Press, 1982.

DANTAS, M. Informação e trabalho no capitalismo contemporâneo. Lua Nova, n.60, p.5-44, 2003.

DATA360a. Home Price Indices (Dallas, Seattle, and Composites). San Francisco, 12 aug. 2007. Disponível em: <http://www.data360.org/graph_group. aspx?Graph_ Group_Id=622>. Acesso em: 12 dez. 2008.

DATA360b. Home Price Index by City [337] - S\&P/Case-Shiller Home Price Index San Diego. San Francisco, 28 mar. 2008. Disponível em: <http://www.data360.org/ dsg.aspx?Data_Set_Group_Id=1946>. Acesso em: 12 dez. 2008.

DAY, J. C. Population Profile of the United States. U.S. Census Bureau. Washington, 8 jul. 2008. Disponível em: <http://www.census.gov/population /www/pop-profile/ natproj.html>. Acesso em: 15 dez. 2008.

DEGUSHI, H. Economics as an Agent-based Complex System: toward agent-based social systems sciences. New York: Springer, 2004. 
DELL'ARICCIA, G.; IGAN, D.; LAEVEN, L. The relationship between the recent boom and the current delinquencies in subprime mortgages. In: FELTON, A.; REINHART, C. (Ed.) The first global financial crisis of the 21st Century. London: VoxEU. org, 2008.

ECONOMIST.COM. Country briefings China: forecast. The Economist Newspaper Limited. London, 1 jul. 2009. Disponível em: <http://www.economist.com / countries/CHINA/profile.cfm?folder=Profile-Forecast>. Acesso em: 4 ago. 2009.

ESPEJO, R.; SCHUHMANN, W.; SCHWANINGER, M.; BILELLO, U. Organizational transformation and learning: a cybernetic approach to management. Chichester: John Wiley \& Sons, 1996.

FOLHA ONLINE. Para principais BCs do mundo, economia mundial se aproxima da recuperação. São Paulo, 9 mar. 2009. Disponível em: <http://wwwl folha.uol.com.br /folha/dinheiro/ult9lu531571.shtml>. Acesso em: 10 mar. 2009.

FINANCIAL FORECAST CENTER. The. U.S. Gross Domestic Product GDP Forecast. Woodlands, TX, 31 jul. 2009. Disponível em: <http://www.forecasts. org/gdp. htm>. Acesso em: 4 ago. 2009.

GHARAJEDAGHI, J. Systems thinking: managing chaos and complexity: a Platform for designing business architecture. New York: Elsevier, 1999.

GLEICK, J. Chaos: making a new science. New York: Penguin Books, 1988.

HIEBERT, P. G. Transforming worldviews: an anthropological understanding of how people change. Grand Rapids: Baker Academics, 2008.

IGOVERNMENT BUREAU. Economic Survey projects India GDP growth at 8.7\%. New Delhi, 28 feb. 2008. Disponível em: <http://www.igovernment.in/site/ economic-survey-projects-india-gdp-growth-at-87/>. Acesso em: 15 dez. 2008.

JACKSON, M. C. System approaches to management. New York: Springer, 2000.

KREGEL, J. Minsky's Cushions of Safety: systemic risk and the crisis in the U.S. subprime mortgage market. Public Policy Brief, n.93, 2008.

LETHBRIDGE, T. Para que servem os analistas? Revista Exame. São Paulo, n.23 p.209, 2008.

LINTON, R. Universal ethical principles: an anthropological view. In: ANSHEN, R. (Ed.) Moral principles of action. New York: Harpes, 1952. p. 645-60.

LOJKINE, J. La Révolution informationnelle. Paris: PUF, 1992.

MARCH, J. The porsuit of organizatinal intelligence: decisions and learning in organizations. New York: Blackwell Publishing, 1999.

MITROFF, I. I.; ANAGNOS, G. Managing crises before they happen: what every executive and manager needs to know about crisis management. New York: Amacom, 2000.

MORIN, E. Introdução ao Pensamento Complexo. Porto Alegre: Sulina, 2007.

OGBURN, W. F.; NIMKOF, M. F. A Handbook of Sociology. London: Routledge \& Kegan Paul Ltd., 1953.

PLOTNITSKY, A. Complementarity: anti-epistemology after Bohr and Derrida. Durham, NC: Duke University Press, 1994. 
PRIGOGINE, I. As leis do caos. Trad. R. L. Ferreira. São Paulo: Unesp, 2002.

REINHART, C. N.; ROGOFF, K. S. Is the 2007 US sub-prime financial crisis so different? An international historical comparison. American Economic Review: Papers and Proceedings, v.98, n.2, p.339-44, 2008.

ROTHWELL, W. J. Workplace learning es performance roles: present and future roles and competencies. New York: American Society for Training and Development, 2000.

SANTAELLA, L. Culturas e artes do pós-humano: da cultura das mídias à cibercultura. São Paulo: Paulus, 2003.

SAXENIAN, A. The new argonauts: regional advantage in a global economy. Cambridge: Harvard University Press, 2006.

SCHECHTER, D. Plunder: investigating our economic calamity and the subprime scandal. New York: Cosimo, 2008.

SHANNON, C. E. A Mathematical Theory of Communication. Bell Syst. Tech., v.27, p.379-423, jul. 1948. Press, 1949.

The Mathematical Theory of Communication. Chicago: University of Illinois

SHILLER, R. J. The subprime solution: how today's global financial crisis happened, and what to do about it. Princeton: Princeton University Press, 2008.

TAKAYAMA, A. Mathematical economics. Cambridge: Cambridge University Press, 1985.

TERRA, L. A. A.; PASSADOR, J. L. Symbiotic Dynamic: The Strategic Problem from the Perspective of Complexity. Systems Research and Behavioral Science, v.33, n.2, p.235-48, 2016.

TESFATSION, L. Agent-based computational economics: modeling economies as complex adaptive systems. Information Sciences, v.149, n.4, p.263-9, feb. 2003.

THOMAS, G. S. Where paychecks are growing fastest. Bizjournals, Washington, 4 jun. 2007. Disponível em: <http://www.bizjournals.com/edit_special/52.html>. Acesso em: 12 out. 2008.

ULMER, R. R.; SELLNOW, T. L.; SEEER, M. W. Effective crisis communication: moving from crisis to opportunity. New York: Sage, 2006.

VERPLANKEN, B.; SVENSON, O. Personal involvement in human decision-making: On conceptualizations and effects on decision processes. In: RANYARD, R.; CROZIER, W. R.; SVENSON, O. (Ed) Decision making: Cognitive models and explanations. London: Routledge, 1997.

WEBER, M. A ética protestante e o espirito do capitalismo. São Paulo: Pioneira, 1996.

WIENER, N. The human use of human beings: cybernetics and society. New York: Doubleday, 1954.

WILSON, D.; PURUSHOTHAMAN, R. Dreaming with BRICs: The Path to 2050. Global Economics, n.99, oct. 2003. Disponível em: <http://www2. goldmansachs. com/ideas/brics/book/99-dreaming.pdf>. Acesso em: 15 dez. 2008.

WOLK, M. Job growth fails to explain soaring home prices: Many states see huge housing demand despite modest employment figures. MSNBC.COM, Washington, 15 jul. 2005. Disponível em: <http://www.msnbc.msn.com/id/8586344/>. Acesso em: 12 dez. 2008. 
RESUMO - No contexto contemporâneo, a economia global pode ser descrita como um sistema baseado em agentes que, quando associados, manifestam seus próprios meios e fins. A crise das hipotecas subprime nos Estados Unidos é um bom exemplo das implicações desse tipo de relacionamento. Ela está diretamente relacionada a poderosos laços de realimentação, compostos por uma série de variáveis que amplificaram o fato de as famílias americanas terem se endividado em ritmo maior do que a sua distribuição de riqueza, prejudicada pela externalização da produção. Há atualmente uma nova estrutura na economia internacional, em que as ex-nações subdesenvolvidas estão mais bem posicionadas no cenário macroeconômico e têm maior poder do que antes - uma consequência do necessário rearranjo sistêmico. Diante dessa complexa dinâmica, a função de inteligência que deveria controlar e garantir a estabilidade sistêmica falhou em perceber a dinâmica e os impactos da nova cultura atrelada ao comportamento do capital contemporâneo, para evitar a perda da hegemonia. Observando-se ex post facto, por meio de um enfoque sistêmico, a crise econômica americana pode ser definida como tendo suas raízes nas premissas de todo o arcabouço cultural da globalização que acabou por conduzir à externalização da produção. Assim, o contexto sistêmico desta análise aponta que a cultura, como importante gerador e amplificador, deve ser o principal foco dos intentos de análise do atual contexto socioeconômico global.

PALAVRAS-CHAVE: Globalização, Pensamento sistêmico, Crise do subprime, Transferência de riqueza, Sistemas baseados em agentes.

ABSTRACT - In the contemporary context, the global economy can be described as a system based on agents that, as a whole, reveal their own means and ends. The subprime mortgage crisis in the United States is a good example of the implications of such relationshyips, for it was directly related to powerful feedback loops comprising a number of variables that amplified the fact that American families had incurred more debts than their share of the national wealth, enhanced by the outsourcing of production. There is now a new structure in the international economy, in which the former underdeveloped nations are better positioned in the macroeconomic scenario and have greater power than before - a consequence of the necessary systemic rearrangement. Given this complex dynamics, the intelligence function that should monitor and ensure systemic stability failed to be effective and misunderstood the dynamics and the impacts of the capitalist cultural elements in order to avoid losing its hegemony. Observing through a systemic approach, the American economic crisis can be defined as rooted in the premises of the entire framework of cultural globalization that eventually led to the outsourcing of production. Thus, the systemic context of this analysis shows that culture, as an important generator and amplifier, should be the main focus of any attempt to analyze the current global socioeconomic context.

KErWORDS: Globalization, Systems thinking, Subprime mortgage crisis, Transference of wealth, Agent based systems.

Christian Carvalho Ganzert é doutor pela Faculdade de Economia, Administração e Contabilidade da USP de Ribeirão Preto. @-ganzert@usp.br

Leonardo Augusto Amaral Terra é doutor na Faculdade de Economia, Administração e Contabilidade da USP de Ribeirão Preto. @- prof@leoterra.com.br 
Dante Pinheiro Martinelli é professor titular na Faculdade de Economia, Administração e Contabilidade da USP de Ribeirão Preto. @ - dantepm@usp.br

Recebido em 22.4.2013 e aceito em 3.10.2013.

I, II e III Faculdade de Economia, Administração e Contabilidade de Ribeirão Preto, Universidade de São Paulo, Ribeirão Preto/São Paulo, Brasil. 